\title{
Y frente al Tabaquismo, ¿podemos hacer más?
}

Q ue el tabaquismo es la primera causa evitable de enfermedad y muerte en los países desarrollados es una frase tan repetida que no sorprende, hoy en día, a ningún profesional de la sanidad. Que el tabaco provoca la muerte de más de 50.000 personas al año en España, considerándose muertes prematuras una cuarta parte de las mismas, es un tema que se repite periódicamente en la mayoría de las publicaciones y cursos de formación sobre esta enfermedad adictiva. Que la mitad de las personas que fuman habitualmente morirá a causa de una enfermedad originada por el tabaco no parece tampoco tener el impacto suficiente entre los profesionales de la salud y entre la población general ni aún insistiendo en que la mitad es uno de cada dos. Y, finalmente, que un simple consejo breve dado por una enfermera o un médico consiga que entre un $2,5 \%$ y un $10 \%$ de fumadores abandonen este hábito es una cuestión tan repetida que atraviesa la barrera de lo importante para situarse entre la irrelevancia de lo cotidiano.

La información sobre los efectos perniciosos del tabaco se repite incansablemente en documentos, publicaciones, cursos monográficos e incluso entre las páginas de sanidad de la prensa diaria. Pero, ¿tenemos todos los sanitarios verdaderamente conciencia de la magnitud de este problema? o, dicho de otro modo, si nos basamos en los datos de la última Encuesta Nacional de Salud, realizada en 2006, y consideramos que fuma habitualmente entre un 27 y un $36 \%$ de la población de 16 a 64 años (en un cupo con 1.400 pacientes entre esas edades, fuman entre 378 y 504 personas: entre 378 y 504 personas que pasan, en su mayoría, en alguna ocasión por nuestra consulta médica o de enfermería, solicitándonos ayuda en cualquier materia de salud), ¿tenemos realmente conciencia de la ayuda que podemos ofrecerles si abordamos su consumo de tabaco? Quizá cada lector pueda ayudar a responder esta cuestión planteándose qué hace habitualmente al respecto cuando la consulta transcurre con un retraso considerable y llega un paciente poco frecuentador por un problema de salud menor que se soluciona en dos minutos: ¿se anima por la recuperación del tiempo "perdido" o le pregunta directamente si fuma?. Si el profesional observa en esta situación una oportunidad de abordar un posible problema de tabaquismo, parece innegable su concienciación.

Pero, ¿los médicos de familia y enfermeras de atención primaria podemos hacer más? Sin lugar a dudas: practicar la prevención primaria. Esta debería comenzar en nuestras consultas reforzando la actitud del no fumador, pero podríamos llevarla más allá de nuestros centros de salud. Con el objetivo de reducir el número de personas que se incorporan a la población fumadora, podríamos llevar a cabo actividades de educación para la salud que informen a la comunidad sobre los efectos nocivos del tabaco y, quizá con un enfoque más acertado, sobre los beneficios de no fumar. La población diana prioritaria debería ser la formada por preadolescentes y adolescentes y el medio natural para las actividades sería la escuela. Bruvold comprueba, tras un metaanálisis realizado en los años noventa, que los mejores programas de prevención del tabaquismo en el ámbito escolar son aquellos que se basan en el tratamiento de las normas y competencias sociales, potencian el desarrollo de habilidades para reconocer y resistir la presión social, incluyen una participación activa con técnicas de discusión, role-playing y el compromiso público de no fumar, y planifican al menos cinco sesiones a lo largo del curso escolar.

La Sociedad Castellano-Manchega de Medicina de Familia y Comunitaria comenzó en el curso 2005/06, en el marco de un convenio con la Consejería de Sanidad de la Junta de Comunidades de Castilla-La Mancha, una serie de charlas-taller que pretendían informar a nuestros escolares de $1^{\circ}$ y $2^{\circ}$ de la ESO sobre los efectos del tabaquismo incluyendo, precisamente, dinámicas encaminadas a reconocer y vencer la presión de grupo. La actividad se extendió por numerosos centros de enseñanza de nuestra Comunidad gracias, como casi siempre, al entusiasmo de un grupo de profesionales médicos y de enfermería que desarrollaron estas actividades, situándolas, por importancia, entre aquellas de alta prioridad. Algunos de ellos, incluso, ya realizaban individualmente charlas dirigidas a los escolares de su zona básica de salud desde hacía años y esto supuso una puesta en común o una unificación de criterios con otros profesionales que desarrollaban su labor en puntos bien distantes de la Comunidad Autónoma.

Un año más tarde, nuestra Sociedad pasó a colaborar con la Red Española de Prevención de Tabaquismo y desarolló en Castilla-La Mancha la primera edición del concurso "Clase sin humo". Clase sin humo es un programa promovido desde la Unión Europea, en el que participan varias Comunidades Autónomas y Ayuntamientos de nuestro país y 21 países europeos, que pretende prevenir o retrasar el inicio en el hábito tabáquico mediante el refuerzo de habilidades que permiten crear en el grupo de jóvenes una presión positiva a favor de mantenerse como no fumadores. La participación es voluntaria y el programa se implementa durante varias sesiones en horario de tuto- 
rías entre los meses de Diciembre y Mayo, en las cuales el tutor y los alumnos se comprometen a no fumar y a elaborar un eslogan de prevención del tabaquismo con su correspondiente representación gráfica. En nuestra Comunidad, con el fin de potenciar el programa observando las recomendaciones de Bruvold, Clase sin humo incorpora seis dinámicas más que pretenden fomentar la asertividad para decir no al tabaco, desenmascarar sus mitos, advertir sobre los efectos de la publicidad indirecta del tabaco e informar sobre los efectos perniciosos del mismo y los beneficios de no fumar. Al finalizar el periodo de actividades, y coincidiendo con la Semana sin Humo de semFYC y el Día Mundial sin Tabaco, se entregan los premios a los mejores eslóganes provinciales y regional consistentes en un viaje para toda la clase y su tutor para realizar actividades en un parque temático o en la naturaleza. En la segunda edición, en el presente curso, ha aumentado la participación de las aulas hasta en un $100 \%$ en algunas provincias y hemos llegado a intervenir sobre 7.281 escolares de $2^{\circ}$ de la ESO.

Pero, además de motivar y facilitar la deshabituación del fumador y prevenir la incorporación de los adolescentes a esta adicción, ¿los médicos de familia y enfermeras de atención primaria podemos hacer más? Sencillamente recordar que la corriente de humo secundaria originada por la combustión del cigarrillo de nuestros pacientes fumadores también afecta a los no fumadores. El tabaquismo pasivo se considera la tercera causa de muerte evitable en países de nuestro entorno, habiéndose relacionado ya en los años ochenta con el cáncer de pulmón y, posteriormente, con el de senos paranasales y mama, enfermedades respiratorias y del oído medio agudas y crónicas, enfermedad coronaria isquémica y síndrome de muerte súbita del lactante. En 2006, la Comisión Europea, a través de su campaña "Help, por una vida sin tabaco", estimaba que el humo el tabaco provoca cada año en Europa la muerte de 19.000 personas que no fuman. La dimensión del problema ¿no nos obliga a abordar al fumador pasivo? La semFYC acaba de publicar, con motivo de la IX Semana sin Humo, una guía breve sobre tabaquismo titulada por primera vez "Guía para el tratamiento del tabaquismo activo y pasivo". En ella se recomienda preguntar a todos los no fumadores su nivel de exposición al humo del tabaco dentro y fuera del hogar, valorar sus conocimientos sobre el tabaquismo pasivo, informarle de forma personalizada sobre los efectos para su salud y aconsejarle evitar la exposición al aire contaminado por el humo del tabaco. Sólo con una verdadera conciencia social sobre las consecuencias del tabaquismo pasivo y la exigencia por parte de la población de cada vez más espacios sin humo se puede conseguir minimizar este grave problema de salud derivado del aire contaminado por el humo del tabaco.

Preguntar a una persona si fuma y, en caso afirmativo, si quiere dejar de fumar y ofrecerle nuestra ayuda no ocupa más de un minuto de consulta. Motivar a un fumador preguntándole, simplemente, por qué fuma no lleva más de dos minutos. El pediatra puede aconsejar a los niños, incluso antes de los 10 años, que no prueben un cigarro, informarles de que el tabaco provoca graves daños y motivar a los padres fumadores para que abandonen el hábito en pocos minutos. El médico de familia que trabaja en urgencias puede aconsejar al enfermo que ha atendido que deje de fumar e informarle de que en su centro de salud le pueden ayudar sin que se retrase por ello la atención a las demás urgencias. Aconsejar a la población solicitar y utilizar espacios sin humo es algo a lo que quizá nos deberíamos acostumbrar en una especialidad que lleva el apellido de "comunitaria". La Oficina Regional Europea de la OMS destaca que la medida de Salud Pública más importante que un país puede tomar en beneficio de su salud y su economía es la reducción en el consumo de tabaco. Y diversos estudios sitúan las intervenciones para dejar de fumar entre las de mejor relación coste-efectividad por delante del tratamiento de la hipertensión o la hipercolesterolemia. La reflexión de estos datos puede ayudarnos a valorar si el esfuerzo en tiempo, por nuestra parte, y en medios, por parte de nuestra administración sanitaria, merece la pena.

Pero, frente al tabaquismo ¿los médicos de familia y enfermeras de atención primaria podemos hacer aún más? Dejo el papel de liderazgo y la función modélica de los sanitarios para reflexión del lector que, a estas alturas del párrafo, pueda estar experimentando una necesidad imperiosa de fumar.

Alejandro Villena Ferrer

Presidente de la Sociedad Castellano-Manchega de Medicina de Familia y Comunitaria

\section{LECTURAS RECOMENDADAS}

1. Cabezas Peña C, Robledo de Dios T, Marqués F, Ortega Sánchez-Pinilla R, Nebot Adell M, Megido Badía MJ et al. Recomendaciones sobre el estilo de vida. Consumo de tabaco. Actualización PAPPS 2007. Aten Primaria 2007; 39 (Supl 3): 29-34.

2. Clemente Jiménez ML, Pérez Trullén A, Bartolomé Moreno C, Cascán Herreros MP. Papel del médico en el control del tabaquismo. En Jiménez-Ruiz CA, Fagerström KO editores. Tratado de tabaquismo $2^{\mathrm{a}}$ ed. Majadahonda: Ergon; 2007. p. 439-454.

3. Mataix Sancho J, Cabezas Peña C, Lozano Fernández J, Camarelles Guillem F, Ortega Cuelva G. Grupo de Abordaje del Tabaquismo de semFYC y de Educación para la salud del PAPPS-semFYC. Guía para el tratamiento del tabaquismo activo y pasivo. Barcelona: semfyc ediciones; 2008.

4. Ariza C, Nebot M. La prevención primaria del tabaquismo: un planteamiento integral. Prevención del Tabaquismo 2004; 6 (2): 68-83 